UDC 17:316

LBC 87.6

\title{
NON-ACCIDENTAL MEETINGS: HOW TECHNOLOGIES ARE KNOWN THROUGH DATING AND RELATIONSHIPS IN THE POSTMODERN SOCIETY ${ }^{1}$
}

\author{
Ekaterina A. Urusova \\ Nizhny Novgorod State Pedagogical University. Kozma Minina (Minin University), \\ Nizhny Novgorod, Russian Federation
}

Timur M. Khusyainov

National Research University Higher School of Economics, Nizhny Novgorod, Russian Federation

\begin{abstract}
In this paper, an attempt to understand modern romantic relationships influenced by technology is made. According to Z. Bauman and E. Giddens, relations in modern society can be characterized as "liquid love" or "confluent love", which are very dynamic. It is noted that the primary stages of building relationships are mediated by technical means, and the partners communicate remotely, according to the "subject - means - subject" scheme. At the same time, the technologies themselves, imperceptibly for users, can control the choice of a partner and limit the range of persons with whom he or she can get acquainted, and as a result, establish a relationship. This is the manifestation of the technical side of rational love, based on the choice of a "suitable life partner". In this case, the theory of rational choice is absolutized, and as a result a partner that meets certain parameters is selected: on the one hand, attractive for the subject, and on the other, equal in social status and level of attractiveness for others. In addition, online dating supports a person's desire for safety and comfort, as technology mitigates failures, and rational risk is only partially present. A person gets the opportunity to explore the Other before a personal meeting, and in some cases even before they meet and begin virtual communication, which is associated with greater openness of users on the global Internet, active placement of various content and personal information. Thus, the search and attraction of a partner in dating services and virtual social networks reflects such tendencies of present as digitalization, macdonalization and virtualization.
\end{abstract} relations.

Key words: postmodern society, love, economization, rationalization, liquid love, liquid life, interpersonal

УДК 17:316

ББК 87.6

\section{НЕСЛУЧАЙНЫЕ ВСТРЕЧИ: КАК ТЕХНОЛОГИЗИРУЮТСЯ ЗНАКОМСТВА И ОТНОШЕНИЯ В УСЛОВИЯХ ОБЩЕСТВА ПОСТМОДЕРНА ${ }^{1}$}

\author{
Екатерина Александровна Урусова
}

Нижегородский государственный педагогический университет им. Козьмы Минина (Мининский университет), г. Нижний Новгород, Российская Федерация

\section{Тимур Маратович Хусяинов}

Национальный исследовательский университет «Высшая школа экономики», г. Нижний Новгород, Российская Федерация

Аннотация. В данной работе делается попытка осмысления современных романтических отношений в контексте влияния на них технологий. По мнению 3. Баумана и Э. Гидденса, отношения в современном обществе могут быть охарактеризованы как «текучая любовь» или «конфлюентная любовь», которые характеризуются большой динамичностью. Отмечается, что первичные этапы построения отношений опосредованы техническими средствами, а коммуникация партнеров происходит дистанционно, по схеме «субъект - 
средство - субъект». При этом сами технологии незаметно для пользователей могут управлять выбором партнера и ограничивать круг лиц, с которыми он может познакомиться и, как следствие, завязать отношения. Так проявляется техническая сторона рациональной любви, основанной на выборе «подходящего спутника жизни». В данном случае абсолютизируется теория рационального выбора, в результате чего происходит подбор партнера, соответствующего определенным параметрам: с одной стороны, привлекательного для субъекта, а с другой - равного по социальному статусу и уровню привлекательности для других. Кроме того, знакомства в сети поддерживают стремление человека к безопасности и комфорту, так как технологии смягчают отказы и минимизируют неудачи, а рациональный риск присутствует лишь частично. Человек получает возможность изучить Другого еще до личной встречи, а в некоторых случаях даже до знакомства и начала виртуальной коммуникации, что связано с большей открытостью пользователей в глобальной сети Интернет, активным размещением различного контента, личной информации. Таким образом, поиск и привлечение партнера в дейтинговых сервисах и виртуальных социальных сетях отражают такие тенденции современности, как цифровизация, макдонильдизация и виртуализация.

Ключевые слова: общество постмодерна, любовь, экономизация, рационализация, текучая любовь, текучая жизнь, межличностные отношения.

\section{Введение}

Современный индивидуализированный мир имеет множество отличий от всех предыдущих эпох: меняются орудия труда, отношение к свободе личности, правам и обязанностям человека. Вместе с ними трансформируется и образ жизни человека, его отношение к семье, партнеру, межличностным отношениям в целом. Само построение контакта с Другим зачастую происходит с помощью цифровых технологий, а чувства и эмоции, возникающие в процессе подобной коммуникации, опосредуются средствами связи и претерпевают изменения. Проявление интеpeca, симпатии и привязанности происходит иначе, чем ранее. Большое значение начинают приобретать «символы» и «образы» отношения к Другому, которые не всегда передают его смысл или выражают глубину чувств.

Подобное происходит ввиду того, что в условиях массовой информатизации меняются процесс и формы коммуникации, общение начинает опосредоваться все большим числом различных устройств и сервисов, передающих не только текст, но изображение, звук, а в некоторых случаях и тактильные ощущения. На смену письмам приходят электронные сообщения, вместо образов в фантазиях, портретов и медальонов с фотографиями появляются цифровые фотографии и видео в высоком разрешении, а объявления в газетах сменяются анкетами на специализированных сайтах.

И все же человек стремится построить близкие доверительные отношения с Другим, поскольку хочет удовлетворить свою потребность в принятии и любви (физической или духовной). Подобный спрос со стороны общества приводит к распространению числа площадок для поиска партнера, создатели которых обещают пользователям многочисленные и успешные знакомства. Технологизация первичного межличностного контакта в сети Интернет, его непосредственность и легкость значительно ускоряют процессы ухаживания, влюбленности, начала отношений.

Вместе с этим стоит отметить еще и то, что само понимание близких и любовных отношений, а также представления о любви трансформируются в рамках конкретного этапа социального развития, хотя общий ее контекст поддерживается и передается социальными институтами [6].

\section{«Текучая» и «конфлюентная любовь»: поиск новой рациональности}

Чувство любви относится к числу экзистенциальных категорий человеческого бытия и занимает одно из важнейших мест в культуре и искусстве. Начиная с эпохи Нового времени, любовь воспринималась через призму романтики, с одной стороны, и рациональности - с другой. Неразделимый комплекс романтической любви и брака, существовавший под влиянием идеи о подлинной любви, которая находится лишь однажды (единожды) в жизни, обеспечивал стабильность таких отношений. Поэтому большое значение придавалось этапу выбора партнера и «традиционному» ритуалу знакомства, так как в 
условиях этого времени большинство браков заключалось до смерти одного из супругов. И при этом, по мнению В.Н. Волкова, между романтической любовью и сексуальным партнерством было установлено четкое равенство [4].

На современном же этапе развития общества отмечается существенная трансформация в сфере интимности, сексуальности, семьи и отношений. Особую роль начинает приобретать коммуникация, которая обеспечивает знакомство и является первичным этапом на пути построения близких отношений. Как отмечали Л. Фейербах, К. Ясперс, М. Хайдеггер и др., любовь, как и само бытие человека, невозможна без коммуникации с другими Я, подлинного диалога Я - Ты [10], а он в современном мире часто происходит дистанционно и опосредован техническими средствами. Оторванная от личности коммуникация, превращенная во взаимодействие по схеме «субъект - средство - субъект», не только увеличивает разрыв между партнерами, но и вносит в процесс построения отношений элемент геймификации. Это значит, что общение может не только увлечь, но и наскучить, как игра, от которой можно отказаться и перейти к другой - новой, динамичной и незнакомой.

По утверждению 3. Баумана, наступает эпоха «текучей любви» на фоне всей «текучести» современности, в которой «искусство любви» заменено коммодифицированной имитацией [17]. Человек в этих условиях должен постоянно создавать временные связи, которые будут, с одной стороны, достаточно свободны, чтобы не стеснять его в действиях, а с другой - достаточно плотны, чтобы дать ему чувство безопасности [18]. В условиях «текучей современности» человек постоянно действует, в том числе и в сфере отношений, знакомясь с новыми людьми, находя новых партнеров. При этом качество отношений окончательно заменяется их количеством. Анализируя труды 3. Баумана, Дж. Барракет и М.С. Генри-Варинг [17] отмечали достаточно критичное отношение автора к феномену онлайн-знакомств, которые, по его мнению, соответствуют условиям рационального выбора наступившей эпохи.

Знакомства, происходящие в глобальной сети Интернет, в полной мере согласуются с концепцией текучей любви 3. Баумана, кото- рая представляет собой среду, подобную коммерческой, где отношения формируются как индивидуалистическая деятельность, основанная на рациональном выборе [17].

Схожие мысли выражает социолог Э. Гидденс, который предложил понятие «конфлюентная любовь», характеризующееся тремя основными аспектами: «Первое, сексуальность становится непременным и основным компонентом любовных отношений. Второе, ценным в любви оказывается не объект любви, который не воспринимается более в качестве неповторимого, единственного и в идеале обретенного навсегда, а сами отношения как факт осуществляющейся жизни. Третье, это - текучая, преходящая любовь» [1, с. 209]. В отличие от романтической любви, «конфлюентная» не содержит в себе идеала и сопутствующего ему комплекса мотивов, установок, ожиданий, жестов, этических и речевых установок. «Конфлюентная любовь» как концепт включает лишь нравы [1], которые распространяются на все этапы построения отношений.

Для лучшего понимания происходящих изменений В.Ф. Шаповалов, говоря о замене возвышенного понимания любви одномоментными связями, предлагает использовать термин «жидкая любовь», которая распространена среди «жидких людей» в «жидком обществе», и составляет их «жидкую жизнь» $[15$, с. 48].

Интересным в этой ситуации является смещение фокуса «обладания» с человека объекта любви - на саму любовь как объект. Так, В.Ф. Шаповалов, поддерживая позицию Э. Фромма, пишет о том, что любовь - это абстракция, а любить - это форма продуктивной деятельности, в которой присутствует деятельностный акт, то есть проявление созидательных чувств в самом человеке [11; 12]. В отрыве от внутренних чувств истинная (плодотворная) любовь превращается в проекцию на символическое проявление. То есть, как отмечает В.Ф. Шаповалов, все чаще возникает явление «обладания», собственничества в отношении партнера - объекта любви [16]. Неплодотворная любовь, основанная на желаниях «покорить» и «заполучить в собственность» партнера, по сути, является стимуляцией интереса Другого, а не проявлением собственного интереса к нему. То есть вместо 
самообновления и самообогащения в отношениях и общении проявляются эгоцентризм и контроль.

В то же время у Э. Гидденса именно любовь как отношение имеет максимальную ценность, по сути, именно любовь с ее абстракцией становится объектом. В условиях когнитивизации экономики и роста значения постматериальных ценностей любовь становится одной из них. Любовь и брак уже не представляют собой товар, как это было в условиях развивающегося капитализма, а отношения уже не так напоминают рынок, как это было в эпоху Нового времени [7]. Согласно Р. Инглхарту, происходит отход от жестких норм, которые имели функциональную необходимость в аграрном обществе. Большее значение начинают приобретать нормы, ориентированные не на обеспечение выживания, а на стремление к достижению индивидуального благополучия [5]. В обществе «текучей современности» 3. Баумана человек стремится создать баланс между свободой (счастьем) и безопасностью [2], и теперь он готов идти на соизмеримый риск, чтобы достичь личного счастья. Так, возникают практики «Вечеров быстрых знакомств» [3], наполненные рациональностью сознательного риска, в ходе которых участники соглашаются на встречу с неизвестными в обмен на шанс встретить подходящего партнера.

Однако, если быстрые свидания предполагают межличностную коммуникацию лицом к лицу и включают в себя возможности получения неодобрения от собеседника в момент общения, есть более «безопасные» способы знакомств, в которых принять знаки симпатии со стороны партнера легко, а шанс получить прямой отказ стремится к нулю. Речь идет о знакомствах в сети Интернет и в дейтинговых сервисах, предлагающих «найти свою любовь». И первое, с чего начинается путь и построение любви, - знакомство, а если быть точными, с перцепции образа предполагаемого партнера.

\section{Знакомство, опосредованное техникой}

Если рассматривать прошлые эпохи, процесс построения отношений был достаточно сложным, с участием большого количества людей - посредников (родственники, друзья) от самого знакомства и до заключения брака. В этом случае личная свобода выбора человека была значительно ограничена или отсутствовала вовсе. В условиях индивидуализации общества, эмансипации и сексуальной революции, повышения личной человеческой свободы снижается роль других людей в этом процессе. При этом человек сам включает в данную коммуникацию посредника в виде технических средств.

Причины этого могут заключаться в самых различных факторах: отсутствие свободного времени, навыков знакомства и близкого общения, а также повышенная вовлеченность в Интернет-коммуникацию. При этом человек получает широкие возможности самопрезентации, так как виртуальное пространство позволяет создать любой образ и использовать любую стратегию при знакомстве $[14,26]$.

Первоначально сайты знакомств представляли достаточно большие базы анкет с несколькими вариантами фильтрации, где пользователь должен был сам искать и подбирать интересных ему людей для дальнейшего знакомства. Со временем произошла революция дейтинговых сервисов, на что оказало значительное влияние развитие цифровых технологий, в частности, нейросетей и машинного обучения. Именно они сделали этот процесс более простым и значительно ускорили подобный поиск, автоматически применяя определенные параметры к базе анкет и предлагая пользователю наиболее «подходящие варианты».

Контакт между пользователями в современных приложениях (например, Tinder) происходит только в случаях взаимного интереca, то есть снижается число неудачных знакомств или нежелательного общения. Фактически здесь проявляются принципы, о которых писал Дж. Ритцер в «Макдональдизации общества» [25]:

- эффективность (снижение рисков, повышение скорости знакомства);

- предсказуемость (ориентация на предпочтения пользователя и предложение вариантов исходя из них);

- калькулируемость (увеличение количества знакомств); 
- контроль (осуществление всего процеса при помощи алгоритмов, автоматизация процесса подбора возможных партнеров, исключение человеческого фактора).

Однако в этих условиях человек вновь сталкивается с ограничением свободы выбора: если ранее эту свободу ограничивали родные, подбирая возможных кандидатов исходя из социальных норм и своих взглядов, то теперь это осуществляет автоматизированная система.

Кроме того, цифровые технологии делают флирт разновидностью развлечения и игры, а досуговый характер интимных и партнерских отношений означает, что они могут быть с легкостью заменены новыми [18]. Так, создатели популярного приложения для знакомств Tinder подчеркнули игровую направленность алгоритма установления контактов, чтобы избавить пользователя от стресса, сопровождающего новые отношения [13].

Первоначальная регистрация через социальную сеть Facebook давала приложению Tinder возможность получить информацию об интересах пользователя, тех сообществах, в которых он состоит, и о том, с кем у него уже есть дружеские связи. При этом вероятные партнеры часто предлагались на основе взаимных совпадений. Фактически вместо интереса к партнеру, его личности и опыту пользователю предлагался общий интерес, который, с одной стороны, упрощал первые шаги знакомства, а с другой - лишал человека субъектной активности в отношении познания другого. Вместе с этим только общие интересы не являются надежной основой для долговременных отношений и куда более значимую роль играют ожидания и притязания партнеров, а также их сочетание.

При этом, как отмечает Джесси Тафт из Cornell Tech, пользователи дейтинговых cepвисов не всегда и не в полной мере знают, чего хотят, а их интимные предпочтения очень динамичны и влияют на все типы характеристик при выборе партнера. Именно поэтому пользователю могут предлагаться различные партнеры, которые могут помочь отследить «успешные совпадения», причем не только самого пользователя, но и других. Так, повторяется одно и то же решение для разных пользователей, имеющих схожие характеристики [20]. Таким образом, если пользователи не заинтересовались представителями какой-то соци- альной или демографической группы, то данная траектория будет сохранена и экстраполирована на других. Подобные исследования демонстрируют дисбаланс среди предпочтений пользователей дейтинговых приложений: так, наименьшее число сообщений получают афроамериканки, мужчины-азиаты и т. д. [24]. В результате они будут в меньшей степени демонстрироваться другим пользователям. Это приводит к тому, что отдельные небольшие группы становятся дискриминируемыми на данной платформе и получают меньший доступ к ресурсам, меньший шанс на успешный поиск.

При этом, по утверждению самих разработчиков, на платформе существует скрытый рейтинг пользователей под названием «Эло», оценивающий их «желанность» со стороны других. При этом «уровень желанности» рассчитывается не на основании внешней привлекательности, а на интересе к профилю со стороны других пользователей (частота выборов с их стороны, время, проводимое ими в профиле пользователя). Данный механизм можно сравнить с подбором противников одного уровня для схваток друг с другом в компьютерных онлайниграх, так как только в этом случае игра будет интересна. При этом в силу индивидуальных предпочтений каждого пользователя алгоритм нацелен не только на расчет усредненного рейтинга, но и на сопоставление желаний одного пользователя с качествами другого [19].

Еще одна особенность подобных приложений заключается в поиске потенциальных партнеров поблизости. Таким образом происходит и ограничение возможных знакомств путем ограничения радиуса поиска, что делает возможность встречи более реальной, но сокращает количество возможных вариантов. Эта модель реализована во французском приложении «hарpn», в еще большей степени ориентированном на геолокацию. При встрече другого пользователя этого приложения появляется уведомление с его профилем, что, как указано в рекламном слогане, позволяет «найти тех, кто повстречался тебе на пути» [21]. Пользователь имеет возможность отметить тех, кто ему понравился, и, в случае взаимного интереса, начать общение.

Стоит отметить еще одну важную особенность, характеризующую дейтинговые сер- 
висы, - возможность начать общение при условии взаимных интереса и симпатии, которые опираются в основном на понятие о физической привлекательности. Подобные представления могут быть стереотипны и культурно обусловлены, что также предполагает возможное возникновение дискриминации отдельных лиц, не подпадающих под понимание стандартной красоты [8]. Нужно также учитывать и то, что стремление показать себя как физически привлекательного человека приводит к появлению стереотипных способов самопрезентации, причем они могут иметь и гендерную специфику. Это касается также особенностей поведения мужчин и женщин при знакомствах: в целом первым приходится выбирать активную модель поведения, а вторым пассивную. В связи с этим женщины получают больше предложений от мужчин и могут выбирать подходящие для них варианты, а мужчинам остается выбирать из тех, кто согласился на общение с ними [9]. С другой стороны, если интерес мужчин в данном случае направлен на физический облик и его характеристики, то ответный интерес женщин связан с личностными характеристиками и оценкой партнера в целом.

Суммируя все сказанное нами ранее, можно предположить, что любовь утрачивает производственный смысл, однако не теряет в полной мере свои экономическую и рациональную основы. Она, как и прежде, удовлетворяет запросы личности, а сам подбор партнера происходит на основании определенных характеристик. Примером такой модели является подход к рассмотрению любви с позиции экономической социологии, в основу которого ложатся теория обмена и модель эгоистического выбора. Именно такие принципы становятся основой при создании рейтинга пользователей дейтингового сервиса. Таким образом, знакомство между пользователями максимально рационализируется, а теория рационального выбора абсолютизируется.

\section{Построение отношений}

\section{с использованием социальных медиа}

Кроме знакомства посредством специализированных дейтинговых сервисов и приложений, человек не перестает знакомиться слу- чайно на улице или в компании, однако информационные технологии проявляются и здесь: знакомство продолжается в виртуальном пространстве путем «добавления в друзья» в социальных сетях или обменом контактами в различных мессенджерах.

Исследователи в области киберпсихологии отмечают уникальность виртуальных социальных сетей при построении романтических отношений. Так, в ходе исследования пользователей Facebook были выявлены три стратегии поведения: пассивное (чтение информации в личном профиле партнера), активное (знакомство через третью сторону), интерактивное (комментирование действий партнера в социальной сети) [22]. При этом могут быть выделены различные сценарии в зависимости от применения тех или иных стратегий на определенных этапах отношений.

Пространство виртуальных социальных сетей выступает интегральной средой для взаимодействия внутри и вокруг межличностных отношений. Так, миллионы пользователей по всему миру практически постоянно используют социальные сети.

Уникальность данного типа ресурсов заключается в большей открытости пользователей, размещении ими различного контента, указания своих персональных данных, интересов и предпочтений, что приводит к распространению практики онлайн-поиска информации в социальных сетях.

Благодаря постоянному потоку сообщений, медиаконтента и установлению новых связей снижается неопределенность относительно настоящих и вероятных партнеров. Пользователь получает возможность для создания норм и ожиданий в отношениях на основе наблюдений, социального опыта и сторонних источников (литература, кинематограф, СМИ). Эти нормы приводят к формированию последующего поведения [22].

При этом социальные сети, в отличие от дейтинговых сервисов, имеют ряд преимуществ, позволяющих не только искать партнера, но и поддерживать длительное общение в начале знакомства посредством используемого в этих ресурсах контента. Так, наличие общих интересов и увлечений можно легко заметить при просмотре личной страницы партнера (например, участие в одних и тех же 
сообществах, группах, наличие музыкальных совпадений и т. д.). Первоначальный интерес в данном случае поддерживается за счет ярко выраженной общности и тем для общения, которые имеют смысловую нагрузку, рассчитанную на близкое знакомство с личностью (в противовес дейтинговым сервисам, в которых общие интересы прослеживаются только номинально).

При этом сама личная страница превращается в зону обмена, которая подпитывается как обоюдным, так и субъективным интересом. Стремление ближе узнать партнера превращается в желание ознакомиться с его предпочтениями, музыкальными вкусами, историей просмотров или записей. С одной стороны, это помогает расширить представление о личности, однако подобную информацию можно считать лишь первоначальной и не всегда релевантной. Причины этого можно искать в тенденциях создания своего «Виртуального Я», когда презентация себя в сети Интернет основана на стремлении показать свое Идеальное Я или качества, которые и вовсе не присущи личности. Огромное значение играет и визуальная культура, а также идеалы и стереотипы презентации и самовыражения в виртуальной среде. Таким образом, при коммуникации и знакомстве в сети Интернет часто встречаются «Идеальное Я» и «Идеальное Я Другого», в то время как о реальной личности говорить не приходится.

Подобное знакомство может привести к краху ожиданий и разочарованию в выбранном партнере, поскольку узнавание личности происходит уже после длительного общения и восприятия виртуального образа. Сочетание окончания периода влюбленности и разрушение построенного образа приводят к быстрому разрыву отношений без желания поддержать коммуникацию и узнать партнера заново. А дальнейшее стремление найти более подходящего партнера приводит личность все на те же виртуальные площадки, которые помогают «выбрать» наиболее удачный вариант.

\section{Заключение}

Как отмечает В.Н. Волков, в эпоху постмодерна любовь и брак все меньше определяются реальными потребностями и все в большей степени становятся производными от образов сексуальности и семьи, которые конструируют сами индивиды, что санкционирует любые ориентации сексуального поведения и сексуальные практики [4]. В этих условиях отходит на второй план экономизм, а рациональность нацелена на удовлетворение нематериальной потребности в любви или секce, что вовсе не означает подбор партнера на всю жизнь. В условиях, когда смысл любви и партнерских отношений меняется, преобразовывается и принцип их рационализации, технологии выполняют запрос человека на удовлетворение его личных потребностей, при этом ориентируясь на другие принципы, нежели это делали посредники в более ранние эпохи. Партнер воспринимается не с позиции продолжения рода, а исходя из сексуальных и личностных предпочтений, при этом техника не выказывает осуждения и дает свободу предпочтений. Таким образом, происходит изменение мотивов и практик знакомства.

Технологизация в этой сфере не может быть оценена однозначно. Проникновение технологий в интимную сферу приводит к упрощению поиска и начала коммуникации, помогает человеку удовлетворить свои запросы. Социальные сети и специальные сервисы оттеснили на задний план привычные способы и площадки, где завязывались знакомства. Подобная тенденция связана с очевидной легкостью установления таких контактов. Кроме того, они имеют различные функции фильтрации, позволяющие расширить поисковое поле, пользователи получают возможность познакомиться с представителями тех социальных сегментов, с которыми не соприкасаются в повседневной жизни. Виртуальное общение и мониторинг персональных стран позволяют более тщательно изучить человека, прежде чем встретиться с ним лицом к лицу. При этом отношения могут быть легко прекращены при помощи удаления личного профиля или блокировки другого. Однако определенные действия алгоритмов могут приводить к дискриминации ряда пользователей, которые подпадают под определенные критерии.

Еще в конце 1950-х гг. вычислительные машины делали анализ совместимости между людьми на основании общности их интере- 
сов. С развитием и распространением глобальной сети Интернет возникает большое число различных сайтов знакомств. Tinder стал культурным феноменом для современного молодого поколения. Он позволяет найти людей для знакомства за пределами социального окружения [23].

Другая важная составляющая уже сложившихся отношений - коммуникация. Любовные отношения для многих «цифровых аборигенов» - это уже не только удовлетворение личных потребностей, но и признак определенного социального статуса, маркер успешности, что приводит к активной демонстрации «личной жизни» в виртуальном пространстве совместные фотографии, публичные сообщения и т. д. Таким образом, использование современных технологий, предоставляющих возможность постоянной коммуникации между партнерами, приводит к трансформации существовавших прежде отношений.

\section{ПРИМЕЧАНИЕ}

${ }^{1}$ Исследование выполнено при финансовой поддержке РФФИ в рамках научного проекта №18-011-00335 «Коэволюция естественного и искусственного как условие сохранения жизненного мира человека».

\section{СПИСОК ЛИТЕРАТУРЫ}

1. Апресян, Р. Г. Идеал романтической любви в «постромантическую эпоху» / Р. Г. Апресян // Этическая мысль. Вып. 4. - М. : ИФ РАН, 2003. - C. 201-218.

2. Бауман, 3. Индивидуализированное общество / 3. Бауман ; пер. с англ., под ред. В. Л. Иноземцева. - М. : Логос, 2005. - 390 с.

3. Белинская, Д. В. Спид дейтинг как форма добрачных отношений / Д. В. Белинская // Социальноэкономические явления и процессы. - 2015. - Т. 10. №4. - C. 102-105.

4. Волков, В. Н. Семья, эротика, секс и любовь в эпоху постмодерна / В. Н. Волков // Контекст и рефлексия: философия о мире и человеке. - 2014. - № 3. C. 35-57.

5. Инглхарт, Р. Постмодерн: меняющиеся ценности и изменяющиеся общества / Р. Инглхарт // Полис. - 1997. - № 4. - С. 6-32.

6. Кон, И. С. Дружба/ И. С. Кон. -4-е изд., доп. СПб. : Питер, 2005. - 330 c.
7. Кочеров, С. Н. История любви. Любовь в Новое время / С. Н. Кочеров // Credo New. - 2016. №4 4 (88).

8. Мелешников, А. А. Роль интерпретации и оценки физического облика при общении на сайтах знакомств / А. А. Мелешников // Вестник Костромского государственного университета. Серия: Педагогика. Психология. Социокинетика. $-2009 .-$ №4. - C. 166-179.

9. Остапенко, И. А. Гендерная идентичность и самопрезентация в Интернет-коммуникации (Coциально-философский анализ) : дис. ... канд. филос. наук / Остапенко Ирина Алексеевна. - Ростов н/Д, 2004. $-196 \mathrm{c}$.

10. Пятилетова, Л. В. Коммуникативные аспекты феномена любви: любовь как диалог / Л. В. Пятилетова, Ю. Н. Горяева // ФӘН-НАУКА. - 2012. - № 12 (15). - C. $44-46$.

11. Фромм, Э. Иметь или быть? / Э. Фромм. M. : Neoclassic, 2015. $-302 \mathrm{c}$.

12. Фромм, Э. Искусство любить / Э. Фромм. M. : ACT : Neoclassic, 2017. $-256 \mathrm{c}$.

13. Хоббс, М. Текучая любовь? Мобильные приложения для знакомств, секс, отношения и цифровая трансформация сферы интимного / М. Хоббс, С. Оуэн, Л. Гербер // Социальные и гуманитарные науки. Отечественная и зарубежная литература. Серия 11: Социология. Реферативный журнал. 2017. - № 4. - C. 47-53.

14. Чистякова, Г. В. Коммуникативные стратегии и тактики в самопрезентациях (на материале русско- и англоязычных сайтов знакомств) / Г. В. Чистякова, Е. П. Бондарева // Филологические науки. Вопросы теории и практики. - 2014. - № 11 (41), ч. 2. C. 203-207.

15. Шаповалов, В. Ф. Мужчина и женщина. Любовь, семья и брак / В. Ф. Шаповалов. - М. : Амрита, 2010. - $208 \mathrm{c}$.

16. Шаповалов, В. Ф. Социальный смысл любви / В. Ф. Шаповалов // Философия и общество. 2011. - № 2. - C. 37-57.

17. Barraket, J. Getting it on(line): Sociological perspectives on e-dating / J. Barraket, M. S. Henry-Waring // Journal of Sociology. - 2008. - № 44. - P. 149-165.

18. Bauman, Z. Liquid Love: On the Frailty of Human Bonds / Z. Bauman. - Cambridge: Polity, 2003. -176 p.

19. Carr, A. I Found Out My Secret Internal Tinder Rating And Now IWish I Hadn't/A. Carr //FastCompany. Electronic text data. - Mode of access: https://www. fastcompany.com/3054871/whats-your-tinder-scoreinside-the-apps-internal-ranking-system (date of access: 05.11.2018). - Title from screen.

20. Dating apps can do more to fight racial bias and discrimination: report // South China Morning Post. - Electronic text data. - Mode of access: https:// www.scmp.com/lifestyle/family-relationships/article/ 
2168914/dating-apps-can-do-more-fight-racial-biasand (date of access: 05.11.2018). - Title from screen.

21. Dillet, R. Happn Is A Dating App Powered By Real Life Interactions / R. Dillet // TechCrunch. Electronic text data. - Mode of access: https:// techcrunch.com/2014/07/16/happn-is-a-datingapp-powered-by-real-life-interactions/ (date of access: 05.11.2018). - Title from screen.

22. Fox, J. Romantic Relationship Stages and Social Networking Sites: Uncertainty Reduction Strategies and Perceived Relational Norms on Facebook / J. Fox, C. Anderegg // Cyberpsychology, Behavior, and Social Networking. - 2014. - № 17. - P. 685-691.

23. Kao, A. Tinder: True Love or a Nightmare? / A. Kao // Advanced Writing: Pop Culture Intersections. -2016 . - № $16-18 \mathrm{p}$.

24. Love, D. OkCupid cofounder Christian Rudder talks true love and statistical analysis / D. Love // The Daily Dot. - Electronic text data. - Mode of access: https://www.dailydot.com/debug/christianrudder-okcupid-interview/ (date of access: 05.11.2018). Title from screen.

25. Ritzer, G. The McDonaldization of Society / G. Ritzer. - N. Y. : SAGE Publications, 2007. - 320 p.

26. Whitty, M. T. Revealing the 'real' me, searching for the 'actual' you: Presentations of self on an internet dating site / M. T. Whitty // Computers in Human Behavior. - 2008. - Vol. 24. - № 4. - P. 1707-1723.

\section{REFERENCES}

1. Apresyan R.G. Ideal romanticheskoy lyubvi v «postromanticheskuyu epokhu»[The Ideal of Romantic Love in the "Post-Romantic Era"]. Eticheskaya mysl, Vol. 4, Moscow, IPh RAS, 2003, pp. 201-218.

2. Bauman Z. Individualizirovannoe obshchestvo [Individualized Society]. Moscow, Logos Publ., 2005. $390 \mathrm{p}$.

3. Belinskaya D.V. Spid deyting kak forma dobrachnykh otnosheniy [Speed Dating as a Form of Premarital Relationship]. Sotsialno-ekonomicheskie yavleniya i protsessy, 2015, vol. 10, no. 4, pp. 102-105.

4. Volkov V.N. Semya, erotika, seks i lyubov v epokhu postmoderna [Family, Erotic, Sex and Love in the Postmodern Era]. Kontekst i refleksiya: filosofiya o mire i cheloveke, 2014, no. 3, pp. 35-57.

5. Inglhart R. Postmodern: menyayushchiesya tsennosti i izmenyayushchiesya obshchestva [Postmodern: Changing Values and Changing Societies]. Polis, 1997, no. 4, pp. 6-32.

6. Kon I.S. Druzhba [Friendship]. Saint Petersburg, Piter Publ., 2005. 330 p.

7. Kocherov S.N. Istoriya lyubvi. Lyubov v Novoe vremya [Love Story. Love in the New Time].
Credo New, 2016, no. 4(88), p. 4.

8. Meleshnikov A.A. Rol interpretatsii i otsenki fizicheskogo oblika pri obshchenii na saytakh znakomstv [The Role of Interpretation and Evaluation of Physical Appearance When Communicating on Dating Sites]. Vestnik Kostromskogo gosudarstvennogo universiteta. Seriya: Pedagogika. Psikhologiya. Sotsiokinetika, 2009, no. 4, pp. 166-179.

9. Ostapenko I.A. Gendernaya identichnost $i$ samoprezentatsiya $v$ Internet-kommunikatsii (Sotsialno-filosofskiy analiz): dis. ... kand. filos. nauk [Gender Identity and Self-Presentation in Internet Communications (Social-Philosophical Analysis). Cand. philos. sci. diss.]. Rostov-on-Don, 2004. 196 p.

10. Pyatiletova L.V., Goryaeva Yu.N. Kommunikativnye aspekty fenomena lyubvi: lyubov kak dialog [Communicative Aspects of the Phenomenon of Love: Love as a Dialogue]. FONNAUKA, 2012, no. 12 (15), pp. 44-46.

11. Fromm J. Imet ili byt'? [To Have or to Be?]. Moscow, AST; Neoclassic Publ., 2015. 302 p.

12. Fromm J. Iskusstvo lyubit [The Art of Loving]. Moscow, AST; Neoclassic Publ., 2017. 256 p.

13. Hobbs M., Oujen S., Gerber L. Tekuchaya lyubov? Mobilnye prilozheniya dlya znakomstv, seks, otnosheniya i tsifrovaya transformatsiya sfery intimnogo [Liquid Love? Apps for Dating, Sex, Relationships, and the Digital Transformation of Intimacy]. Sotsialnye i gumanitarnye nauki. Otechestvennaya $i$ zarubezhnaya literatura. Seriya 11: Sotsiologiya. Referativnyy zhurnal, 2017, no. 4, pp. 47-53.

14. Chistyakova G.V., Bondareva E.P. Kommunikativnye strategii i taktiki V samoprezentatsiyakh (na materiale russko- i angloyazychnykh saytov znakomstv) [Communicative Strategies and Tactics in Self-Presentations (on the Material of Russian and English Dating Sites)]. Filologicheskie nauki. Voprosy teorii i praktiki, 2014, no. 11 (41), Part II, pp. 203-207.

15. Shapovalov V.F. Muzhchina i zhenshchina. Lyubov, semya i brak [Man and Woman. Love, Family and Marriage]. Moscow, Amrita Publ., 2010. 208 p.

16. Shapovalov V.F. Sotsialnyy smysl lyubvi [Social Meaning of Love]. Filosofiya i obshchestvo, 2011, no. 2, pp. 37-57.

17. Barraket J., Henry-Waring M.S. Getting it on(line): Sociological perspectives on e-dating. Journal of Sociology, 2008, no. 44, pp. 149-165.

18. Bauman Z. Liquid Love: On the Frailty of Human Bonds. Cambridge, Polity, 2003. 176 p.

19. Carr A.I Found Out My Secret Internal Tinder Rating and Now I Wish I Hadn't. FastCompany. URL: https://www.fastcompany.com/3054871/whats-yourtinder-score-inside-the-apps-internal-ranking-system (accessed 5 November 2018). 


\section{ФИЛОСОФИЯ}

20. Dating apps can do more to fight racial bias and discrimination: report. South China Morning Post. URL: https://www.scmp.com/lifestyle/familyrelationships/article/2168914/dating-apps-can-do-morefight-racial-bias-and (accessed 5 November 2018).

21. Dillet R. Happn Is ADating App Powered By Real Life Interactions. TechCrunch. URL: https://techcrunch.com/ 2014/07/16/happn-is-a-dating-app-powered-by-real-lifeinteractions/ (accessed 5 November 2018).

22. Fox J., Anderegg C. Romantic Relationship Stages and Social Networking Sites: Uncertainty Reduction Strategies and Perceived Relational Norms on Facebook. Cyberpsychology, Behavior, and Social Networking, 2014, no. 17, pp. 685-691.
23. Kao A. Tinder: True Love or a Nightmare? Advanced Writing: Pop Culture Intersections, 2016, no. $16.18 \mathrm{p}$.

24. Love D. OkCupid cofounder Christian Rudder talks true love and statistical analysis. The Daily Dot. URL: https://www.dailydot.com/debug/christianrudder-okcupid-interview/ (accessed 5 November 2018).

25. Ritzer G. The McDonaldization of Society. New York, SAGE Publications, 2007. 320 p.

26. Whitty M.T. Revealing the 'real' me, searching for the 'actual' you: Presentations of self on an internet dating site. Computers in Human Behavior, 2008, vol. 24, no. 4, pp. 1707-1723.

\section{Information about the Authors}

Ekaterina A. Urusova, Lecturer, Department of Practical Psychology, Nizhny Novgorod State Pedagogical University. Kozma Minina (Minin University), Ulyanova St., 1, 603005 Nizhny Novgorod, Russian Federation, uk1801@yandex.ru.

Timur M. Khusyainov, Lecturer, Department of Social Sciences, National Research University Higher School of Economics, B. Pecherskaya St., 25/12, 603155 Nizhny Novgorod, Russian Federation, timur@husyainov.ru.

\section{Информация об авторах}

Екатерина Александровна Урусова, преподаватель кафедры практической психологии, Нижегородский государственный педагогический университет им. Козьмы Минина (Мининский университет), ул. Ульянова, 1, 603005 г. Нижний Новгород, Российская Федерация, uk1801@yandex.ru.

Тимур Маратович Хусяинов, преподаватель департамента социальных наук, Национальный исследовательский университет «Высшая школа экономики», ул. Б. Печерская, 25/12, 603155 г. Нижний Новгород, Российская Федерация, timur@husyainov.ru. 